\title{
Optimal Sizing of a Trigeneration Plant Integrated with Total Site System Considering Multi-period and Energy Losses
}

\author{
Khairulnadzmi Jamaluddin ${ }^{1,2}$, Sharifah Rafidah Wan Alwi ${ }^{1,2, *}$, Zainuddin Abd Manan ${ }^{1,2}$, Khaidzir Hamzah $^{2}$ and Jiri \\ Jaromir Klemeš ${ }^{3}$ \\ ${ }^{1}$ Process Systems Engineering Centre (PROSPECT), Research Institute of Sustainable Environment, Universiti Teknologi Malaysia, \\ 81310 UTM Johor Bahru, Malaysia \\ ${ }^{2}$ School of Chemical and Energy Engineering, Faculty of Engineering, Universiti Teknologi Malaysia, 81310 UTM Johor Bahru, \\ Malaysia \\ ${ }^{3}$ Sustainable Process Integration Laboratory-SPIL, NETME Centre, Faculty of Mechanical Engineering, Brno University of \\ Technology-VUT BRNO, Technická 2896/2, 61669 Brno, Czech Republic
}

\begin{abstract}
Rising awareness for the environment as well as concerns over the sustainability of fossil fuels has encouraged developed and developing countries to find alternative ways to enhance the thermal efficiency of current power systems. The thermal efficiency of power plants can be increased from $30-40 \%$ up to 80 $-90 \%$ through the implementation of a trigeneration system by recovering dissipated waste heat for other purposes. The trigeneration system can be defined as a technology that can produce simultaneous power, heating, and cooling energy from the same fuel source. Trigeneration System Cascade Analysis (TriGenSCA) methodology is an optimisation approach based on Pinch Analysis that has been used to establish the guidelines or the proper size of the trigeneration system. This paper proposes a modification of TriGenSCA by considering a multi-period of energy consumption to optimise the size of the utility in the centralised trigeneration system by considering the transmission and storage of energy losses in the Total Site system. There are six steps involved including data extraction, identification of time slices, Problem Table Algorithm (PTA), Multiple Utility Problem Table Algorithm (MU PTA), Total Site Problem Table Algorithm (TS PTA), and modified TriGenSCA. The methodology has been tested on the centralised nuclear trigeneration system in a Total Site System as a case study and results shown that thermal energy needed by the Pressurized Water Reactor (PWR) trigeneration system with transmission losses is 2,427 MW whereas thermal energy needed by the PWR trigeneration system without transmission losses is 2,424 MW. The TriGenSCA with consideration of transmission and storage energy losses is useful for engineers and designers to determine the exact value of energy for trigeneration plant.
\end{abstract}

\section{Introduction}

Rapid technological advancement and rising population growth have led to an increase in energy consumption worldwide. As conventional fossil fuels continue to dominate the energy supply, the threat of fossil fuel depletion and global warming also rises. The World Energy Council [1] has an estimated escalation of total primary energy by $21 \%$ from 2020 to 2040 . Improving thermal efficiency in existing systems is one way to conserve energy; i.e. by using waste heat for other applications such as seawater desalination, district heating and cooling. In this context, trigeneration appears as a suitable technology because it can supply power, heating and cooling energy from the same source of fuel. As stated by Wu and Wang [2], the thermal efficiency of the current system can be improved from $30-40 \%$ to $80-90 \%$ through the use of the trigeneration system.

Optimisation on trigeneration system has been progressively developed, mainly in simulations. A new methodology has been proposed by Cardona and Piacentino [3] to select and manage a trigeneration system based on heat and cool energy demands obtained from several European hotels. Plura et al. [4] made comparisons between different chillers as it is integrated with a trigeneration system. Rong et al. [5] optimised a trigeneration system with storages by using the Lagrangian relaxation-based algorithm. The carbon emissions from the Organic Rankine Cycle trigeneration system is analysed by Al-Sulaiman et al. [6]. Bracco et al. [7] have developed an optimal design of the distributed trigeneration method based on mixed-integer linear programming. Gue et al. [8] developed a trigeneration method via fuzzy linear programming to perform a price sensitivity analysis. The optimal sizing of trigeneration system in the Total Site system has been developed by Jamaluddin et al. [9] through Pinch Analysis (PA) methodology, and recently, Jamaluddin et al. [10] have developed a new numerical-based PA method for batch industrial processes as energy variations at demands site.

\footnotetext{
* Corresponding author: syarifah@utm.my
} 
However, the previous study that was developed by Jamaluddin et al. [10] did not consider energy losses due to the transmission system. This paper proposes a modified Trigeneration System Cascade Analysis (TriGenSCA) by considering energy losses due to transmission and storage systems as well as multi-period energy demands to optimise the sizing centralised trigeneration system utilities. Implementation of this comprehensive approach by considering transmission and storage energy losses may give users the advantage of determining the exact energy requirements which are closer to the actual trigeneration system, as well as minimising the power, heat and cool energy requirements of the utility and the Total Site system in demand fluctuations.

\section{Methodology and Case Study}

This paper extends the insight-based numerical method developed by Jamaluddin et al. [10] to evaluate the optimal size of the centralised trigeneration system for the integration of Total Site Cooling, Heating and Power (TSCHP) in a variety of energy consumption. The overall methodology can be categorised into six steps which are data extraction, construction of time slices, Problem Table Algorithm (PTA), Multiple Utility Problem Table Algorithm (MU PTA), Total Site Problem Table Algorithm (TS PTA), and modified TriGenSCA. The trigeneration system is incorporated into a Pressurized Water Reactor (PWR) nuclear power plant to generate power, heat and cool energy simultaneously for demand requirements. The PWR is chosen because it is zero carbon emission and able to produce continuous energy in a day.

Uranium-235 is used as a fuel in the PWR to produce enormous energy for the generation of Very High-Pressure Steam (VHPS). The PWR trigeneration system produces VHPS from fission processes in the centre of the primary loop, which is then transferred to the secondary loop via a steam generator heat exchanger. The average VHPS temperature is about $300^{\circ} \mathrm{C}$ [11]. The temperature of the VHPS is sufficient to supply power to the double extraction turbine and low-pressure steam such as the High-Pressure Steam (HPS) and Low-Pressure Steam (LPS) generations by the use of the Moisture Separator Reheater (MSR). The MSR is used to superheat the steam and remove moisture in the steam. Excess HPS and LPS will supply more power on demand by condensing it in the condensing turbine. The VHPS can also be converted into HPS and LPS through the relief valve. The condenser is installed to produce hot water (HW) to be supplied directly to the demand needs or recycled back to the steam generator for steam generation. Cooling Water $(\mathrm{CW})$ is generated from the cooling tower via the HW evaporation process. On the other hand, chilled water $(\mathrm{ChW})$ is produced by the absorption refrigerator. Further process of developing $\mathrm{CW}$ and $\mathrm{ChW}$ can be referred to Jamaluddin et al. [10]. Excess energy can be retained in storage facilities and discharged during energy deficits. The lead-acid battery is used as power storage, whereas the thermochemical energy storage system is used for storing heating and cooling energy. In this case study, the assumptions made are:

1. The overall thermal efficiency is $10 \%$ [2].

2. Energy loss from power and thermal storage systems is considered. The capacity of the leadacid battery used for charging power [12] and the inverter [13] is estimated to be $90 \%$. The discharge capacity of the lead-acid battery is $85 \%$ [12]. For the thermal storage device, thermochemical storage is used for charging and discharging up to $58 \%$ [13].

3. Energy conversion is considered in the study where the efficiency of the double extraction turbine, condensing turbine [14], condensation system [15], cooling tower and absorption chiller [16] is assumed to be $30 \%$.

\subsection{Data Extraction}

In the first step, the supply of energy sources for the centralised trigeneration system and the demand from industrial plants are extracted according to the time of operations. The data extraction is divided into two parts which are the power part and the heating/cooling part. To illustrate the suggested approach, two industrial plants power demand data are taken from works of literature which are shown in Figure 1 [17]. For the power generation in PWR as a trigeneration system, the preliminary assumption for initial power in PWR is at a maximum turn-down ratio of $600 \mathrm{MWe}$. The maximum turn-down ratio is known as the full-scale capability of the PWR trigeneration system. The double extraction turbine efficiency is assumed to be $30 \%$ [14], and hence, the total thermal energy needed for the maximum turn-down ratio in trigeneration PWR is 2,000 MWth. The separation of total thermal energy is assumed to be (1) $600 \mathrm{MWe}$ for power; (2) $50 \mathrm{MW}$ for HPS; (3) $150 \mathrm{MW}$ for LPS; (4) 250 MW of HW; (5) $200 \mathrm{MW}$ for CW and (6) $50 \mathrm{MW}$ for ChW.

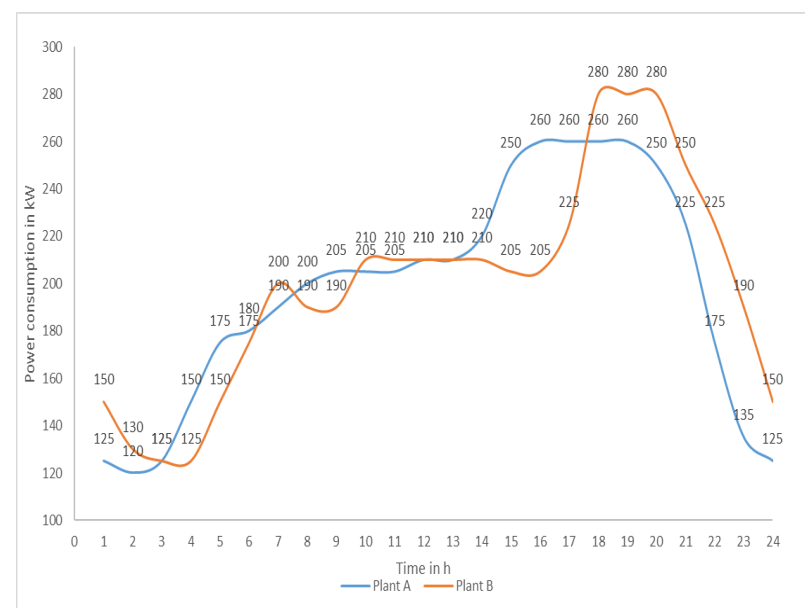

Fig. 1. Power variations for Plants A and B in continuous $24 \mathrm{~h}$ operations [17]

For the heating/cooling part, several data are needed which includes supply temperatures, target temperatures, 
minimum flow rate heat capacity, the time interval for each stream and the minimum temperature difference between processes $\left(\Delta T_{\text {min,pp }}\right)$. Tables 1 and 2 show the stream data in the two industrial plants, namely Plants A and B. The stream data are obtained from Jamaluddin et al. [10]. Shifted cold temperature for process streams is determined. The temperature of the cold streams is added by half of the value of minimum temperature between processes $\left(\Delta T_{\min , p p} / 2\right)$, whereas the temperature of the hot streams is subtracted by half of the value of $\Delta T_{\min , p p} / 2$. In this case study, the values $\Delta T_{\min , p p}$ of Plants A and B are assumed to be $20^{\circ} \mathrm{C}$ and $10^{\circ} \mathrm{C}$. Multiple utility temperature levels are shown in Table 3. The transmission data are also needed to determine energy losses due to transmission. Table 4 shows the data required for transmission.

Table 1. Stream data for Industrial Plant A with $\Delta T_{\min , p p}=$ $20^{\circ} \mathrm{C}$ (obtained from Jamaluddin et al. [10])

\begin{tabular}{|c|c|c|c|c|c|c|c|}
\hline $\begin{array}{c}\text { Strea } \\
\mathrm{m}\end{array}$ & $\begin{array}{c}\mathrm{T}_{\mathrm{s}} \\
\left({ }^{\circ} \mathrm{C}\right)\end{array}$ & $\begin{array}{c}\mathrm{T}_{\mathrm{t}} \\
\left({ }^{\circ} \mathrm{C}\right)\end{array}$ & $\begin{array}{c}\Delta H \\
(\mathrm{MW})\end{array}$ & $\begin{array}{l}\mathrm{mCP} \\
(\mathrm{MW} \\
\left.{ }^{\circ} \mathrm{C}\right)\end{array}$ & $\begin{array}{c}\mathrm{T}_{\mathrm{s}}, \\
\left({ }^{\circ} \mathrm{C}\right)\end{array}$ & $\begin{array}{c}\mathrm{T}_{\mathrm{t}}{ }^{\prime} \\
\left({ }^{\circ} \mathrm{C}\right)\end{array}$ & $\begin{array}{l}\text { Time } \\
\text { (h) }\end{array}$ \\
\hline $\begin{array}{l}\text { C1 } \\
\text { Hot }\end{array}$ & 85 & 5 & 600 & 10 & 75 & 15 & $\begin{array}{c}06- \\
17\end{array}$ \\
\hline $\begin{array}{l}\mathrm{C} 2 \\
\mathrm{Hot}\end{array}$ & 80 & 40 & 400 & 10 & 70 & 30 & $\begin{array}{c}06- \\
17\end{array}$ \\
\hline $\begin{array}{l}\text { C3 } \\
\text { Hot }\end{array}$ & 41 & 38 & 105.3 & 35.1 & 31 & 28 & $\begin{array}{c}20- \\
06\end{array}$ \\
\hline $\begin{array}{c}\mathrm{C} 4 \\
\text { Cold }\end{array}$ & 25 & 65 & 23.6 & 0.59 & 35 & 75 & $\begin{array}{c}20- \\
06\end{array}$ \\
\hline $\begin{array}{c}\text { C5 } \\
\text { Cold }\end{array}$ & 55 & 65 & 25.8 & 2.58 & 65 & 75 & $\begin{array}{c}00- \\
24\end{array}$ \\
\hline $\begin{array}{c}\text { C6 } \\
\text { Cold }\end{array}$ & 33 & 60 & 6.48 & 0.24 & 43 & 70 & $\begin{array}{c}06- \\
17\end{array}$ \\
\hline $\begin{array}{c}\text { C7 } \\
\text { Cold }\end{array}$ & 25 & 60 & 77 & 2.2 & 35 & 70 & $\begin{array}{c}20- \\
06\end{array}$ \\
\hline $\begin{array}{c}\text { C8 } \\
\text { Cold }\end{array}$ & 30 & 240 & 29.4 & 0.14 & 40 & 250 & $\begin{array}{c}06- \\
17\end{array}$ \\
\hline $\begin{array}{c}\text { C9 } \\
\text { Cold }\end{array}$ & 25 & 28 & 150 & 50 & 35 & 38 & $\begin{array}{c}06- \\
17\end{array}$ \\
\hline $\begin{array}{l}\text { C10 } \\
\text { Cold }\end{array}$ & 30 & 100 & 59.5 & 0.85 & 40 & 110 & $\begin{array}{c}00- \\
24\end{array}$ \\
\hline $\begin{array}{l}\text { C11 } \\
\text { Cold }\end{array}$ & 5 & 50 & 315 & 7 & 15 & 60 & $\begin{array}{c}06- \\
17\end{array}$ \\
\hline $\begin{array}{l}\mathrm{C} 12 \\
\text { Cold }\end{array}$ & 21 & 200 & 8.95 & 0.05 & 31 & 210 & $\begin{array}{c}00- \\
24\end{array}$ \\
\hline
\end{tabular}

\subsection{Identification of Time Slices}

The time slices are described as temporal variations in demand streams. The energy requirements at the manufacturing site are time-dependent when batch processes are incorporated. However, energy variations are more significant if other buildings are included in the Total Site System. The time frame can be represented as a time interval with relatively constant energy variation. Based on the case study, the time slices of hot and cold streams are defined in three parts of $20-06 \mathrm{~h}$ (TSL 1), 06 $-17 \mathrm{~h}$ (TSL 2) and $17-20 \mathrm{~h}$ (TSL 3).
Table 2. Stream data for Industrial Plant B with $\Delta T_{\min , p p}=$ $10^{\circ} \mathrm{C}$ (obtained from Jamaluddin et al. [10])

\begin{tabular}{|c|c|c|c|c|c|c|c|}
\hline $\begin{array}{c}\text { Strea } \\
\mathrm{m}\end{array}$ & $\begin{array}{c}\mathrm{T}_{\mathrm{s}} \\
\left({ }^{\circ} \mathrm{C}\right)\end{array}$ & $\begin{array}{c}\mathrm{T}_{\mathrm{t}} \\
\left({ }^{\circ} \mathrm{C}\right)\end{array}$ & $\begin{array}{c}\Delta H \\
(\mathrm{MW})\end{array}$ & $\begin{array}{c}\mathrm{mCP} \\
(\mathrm{MW} \\
\left./{ }^{\circ} \mathrm{C}\right)\end{array}$ & $\begin{array}{c}\mathrm{T}_{\mathrm{s}}{ }^{\circ} \\
\left({ }^{\circ} \mathrm{C}\right)\end{array}$ & $\begin{array}{c}\mathrm{T}_{\mathrm{t}}{ }^{\prime} \\
\left({ }^{\circ} \mathrm{C}\right)\end{array}$ & $\begin{array}{c}\text { Time } \\
(\mathrm{h})\end{array}$ \\
\hline $\begin{array}{c}\mathrm{C} 1 \\
\text { Hot }\end{array}$ & 85 & 5 & 600 & 10 & 75 & 15 & $\begin{array}{c}06- \\
17\end{array}$ \\
\hline $\begin{array}{c}\mathrm{C} 2 \\
\text { Hot }\end{array}$ & 80 & 40 & 400 & 10 & 70 & 30 & $\begin{array}{c}06- \\
17\end{array}$ \\
\hline
\end{tabular}

Table 3. Multiple site utility temperatures

\begin{tabular}{|c|c|}
\hline Utility & Temperature $\left({ }^{\circ} \mathrm{C}\right)$ \\
\hline $\begin{array}{c}\text { High-pressure steam } \\
\text { (HPS) }\end{array}$ & 240 \\
\hline $\begin{array}{c}\text { Low-pressure steam } \\
\text { (LPS) }\end{array}$ & 150 \\
\hline Hot water (HW) & 50 \\
\hline Cooling water $(\mathrm{CW})$ & 20 \\
\hline Chilled water $(\mathrm{ChW})$ & 10 \\
\hline
\end{tabular}

Table 4. Data required for transmission energy losses

\begin{tabular}{|c|c|c|}
\hline & Parameters & Data \\
\hline \multicolumn{2}{|c|}{ Estimated length of transmission for } & $10 \mathrm{~km}$ \\
\hline \multicolumn{2}{|c|}{ Type of insulator for thermal pipeline } & Calcium silicate \\
\hline \multicolumn{2}{|c|}{$\begin{array}{l}\text { Diameter for carbon steel for heating } \\
\text { pipeline [18] }\end{array}$} & $0.1 \mathrm{~m}$ \\
\hline \multicolumn{2}{|c|}{$\begin{array}{l}\text { Diameter for stainless steel for cooling } \\
\text { pipeline [18] }\end{array}$} & $0.1 \mathrm{~m}$ \\
\hline \multicolumn{2}{|c|}{$\begin{array}{l}\text { Heat dissipating capacity of heating } \\
\text { pipeline per unit area [19] }\end{array}$} & $350 \mathrm{~W} / \mathrm{m}^{2}$ \\
\hline \multicolumn{2}{|c|}{$\begin{array}{l}\text { Heat dissipating capacity of cooling } \\
\text { pipeline per unit area [19] }\end{array}$} & $420 \mathrm{~W} / \mathrm{m}^{2}$ \\
\hline \multirow{3}{*}{$\begin{array}{c}\text { Aluminium } \\
\text { Cable Steel } \\
{[20]}\end{array}$} & Resistance & $98.1 \mathrm{~m} \Omega / \mathrm{km}$ \\
\hline & Carrying current capacity & $840 \mathrm{~A}$ \\
\hline & Temperature & $75^{\circ} \mathrm{C}$ \\
\hline
\end{tabular}

\subsection{Construction of Problem Table Algorithm (PTA)}

The development of PTA by Linnhoff and Flower [21] is used to obtain Pinch Point temperature and minimum external heating and cooling energy. The PTA has an advantage because it can give more accurate values as compared with GCC. The PTA is constructed in every part of each plant, and the details of the construction can be found in the works of Linnhoff and Flower [21].

\subsection{Construction of Multiple Utility Problem Table Algorithm (MU PTA)}

Extension of PTA was developed by Liew et al. [22] to determine target potential sources and sinks of multiple utility levels in TSCHP. The method is called MU PTA, and the details of the construction of MU PTA can be referred to Liew et al.'s [22] work. In this case study, the minimum temperature difference between utility and process of Plants $\mathrm{A}$ and $\mathrm{B}$ are assumed $10^{\circ} \mathrm{C}$ and $5^{\circ} \mathrm{C}$.

\subsection{Construction of Total Site Problem Table Algorithm (TS PTA)}

TS PTA has been developed by Liew et al. [22] to obtain the total number of utilities that can be shared between 
processes. The design of the TS PTA is performed in every part of the time slice. Further guidance on the design of the TS PTA can be found in the work of Liew et al. [22].

\subsection{Construction of Modified Trigeneration System Cascade Analysis (TriGenSCA)}

Jamaluddin et al. [10] have established a new methodology for minimising the targeting of power, heating and cooling as well as maximising the efficiency of the trigeneration system. Previously, the method only considers energy losses due to the charging and discharging of storage systems in the study. The method is modified by including energy transmission losses as well in the TriGenSCA. There are three major steps in the production of TriGenSCA, which are the cascade analysis, the estimation of the new size of utility in the trigeneration system and the percentage change between the current and the previous size of utility in the trigeneration system.

\subsubsection{Cascade Analysis}

In the first step, cascade analysis is constructed to determine the estimated utility sizing in the trigeneration system. The cascade analysis can be performed as presented below:

1. Times in $24 \mathrm{~h}$ operations with $1 \mathrm{~h}$ interval are shown in Column 1.

2. The power, heating and cooling generations from the centralised trigeneration system are shown in Column 2. Column 3 described the availability of energy after considering transmission losses. The availability of power from energy losses due to transmission is calculated by using Equation (1) whereas Equation (2) calculates the availability of thermal energy after transmission energy losses. A carbon steel pipeline is used the transfer the heat from the centralised trigeneration system to the industrial plants. On the other hand, stainless steel pipeline is used to transfer the cool to the industrial plants.

$$
W_{\text {power }}=E_{\text {power }}-\left(R_{T} \times I^{2} \times L\right)
$$

Where $\mathrm{W}_{\text {power }}=$ Available power after transmission energy losses in $\mathrm{MW} ; \mathrm{E}_{\text {power }}=$ Power generation in $\mathrm{MW}$; $\mathrm{R}_{\mathrm{T}}=$ Resistance in $\mathrm{m} \Omega / \mathrm{km} ; \mathrm{I}=$ Carrying current capacity in Ampere; $\mathrm{L}=$ length of transmission in $\mathrm{m}$.

$$
W_{\text {heat } / \text { cool }}=E_{\text {heat/cool }}-\left(\pi \times D \times L \times q_{c}\right)
$$

Where $\mathrm{W}_{\text {heat } / \text { cool }}=$ Available heat/cool energy after transmission in MW; $E_{\text {heat } / \text { cool }}=$ Heat $/$ cool energy generation in $\mathrm{MW} ; \mathrm{D}=$ Diameter of heat/cool pipelines in $\mathrm{m} ; \mathrm{q}_{\mathrm{c}}=$ Heat $/$ cool dissipating capacity per unit area in $\mathrm{MW} / \mathrm{m}^{2}$.

3. Column 4 presents the energy demands from industrial plants. The power demands in Column 4 are obtained from the summation of power requirements in Step 1 (cumulative from Figure 1).
On the other hand, the heating and cooling energy demands are obtained based on the TS PTA results from Step 5.

4. The net energy requirement in Column 5 is determined by subtracting available energy from Column 3 with energy demands from Column 4. This represents the generations of available energy supplied to the energy demands at the respective time intervals. The positive value in Column 5 represents the energy surplus, whereas the negative value represents the energy deficit.

5. Column 6 introduces the new net energy requirement, which is accomplished by transferring any excess energy at higher utility temperatures to lower deficit utility temperatures. For example, a surplus of $10.98 \mathrm{MW}$ of HPS can be converted into LPS energy from 18 to $20 \mathrm{~h}$ intervals through a relief valve. Hence, the deficit LPS energy is reduced from 66.71 MW to $55.73 \mathrm{MW}$.

6. The charging and discharging energy losses are considered in Column 7. The lead-acid battery is used as a power storage system, whereas thermochemical is used as thermal storage systems. As stated by Luo et al. [12], the charging and discharging efficiencies of a lead-acid battery are assumed to be $90 \%$ and $85 \%$. Inverter efficiency is also added in the analysis, where it is assumed to be $90 \%$ [13]. The inverter is used to change AC to DC and vice versa. The charging and discharging thermochemical storage system, on the other hand, are assumed to be the same, which is 58\% [13]. Surplus energy (shown in positive value) can be stored in the storage system, and the energy can be discharged from the storage system as the energy is in deficit. The calculation of surplus power is considered by multiplying it with charging and inverter efficiencies. The surplus heat and cool energy are considered by multiplying it with charging efficiency. The deficit power, on the other hand, is divided into discharging and inverter efficiencies. Deficit heat and cool energy are divided into discharging efficiency.

7. The cumulative energy is presented in Column 8. This means that the excess energy is retained in the storage systems at the time interval and will be used again in the subsequent time. The initial energy start-up is considered to be zero. Surplus energy accumulates from the highest to the lowest time intervals. Equation (3) is used to measure the cumulative amount of energy. The negative values in Column 8 indicate the energy shortage where the positive values indicate surplus energy. The highest negative value in this column represents the most energy deficits needed by the system.

$$
E_{i+1}=E_{i}+E_{\text {charging/discharging }}
$$

Where $\mathrm{E}_{\mathrm{i}+1}=$ Cumulative energy for the next time interval in $\mathrm{MWh} ; \mathrm{E}_{\mathrm{i}}=$ Cumulative energy at the current time interval in $\mathrm{MWh}$; $\mathrm{E}_{\text {charging/discharging }}=$ Charging/discharging energy in MWh. 
8. Column 9 presents the new cumulative energy calculated using Equation (3). The highest negative value in Column 8 is converted as a positive value and, as the initial cumulative energy, represents the external energy needed in the storage tank to supply the demand. The surplus energy stored in the storage tank can be collected from the last row of the board. The excess energy in the last row can be moved to the next day to offset the external energy required.

Based on the final cascade analysis, the initial cumulative energy for power is $183 \mathrm{MWh}$, HPS is $19.07 \mathrm{MWh}$, LPS is $308.32 \mathrm{MWh}, \mathrm{HW}$ is $0.61 \mathrm{MWh}$, and $\mathrm{CW}$ is 43.97 $\mathrm{MWh}$. The initial cumulative energy for $\mathrm{ChW}$ is in zero value. The excess energy available for power is 183.16 MWh, HPS is $19.11 \mathrm{MWh}$, LPS is $308.54 \mathrm{MWh}, \mathrm{CW}$ is $44.57 \mathrm{MWh}$, and $\mathrm{ChW}$ is $0.23 \mathrm{MWh}$. The excess HW available for the next day is in zero value. Table 5 shows the simplification of the final cascade analysis iteration.

Table 5a. The simplified final iteration of cascade analysis

\begin{tabular}{|c|c|c|c|c|c|c|}
\hline \multirow[t]{3}{*}{ Time } & \multicolumn{6}{|c|}{ Generation (MW) } \\
\hline & \multirow{2}{*}{ Power } & \multicolumn{3}{|c|}{ Heat } & \multicolumn{2}{|c|}{ Cool } \\
\hline & & HPS & LPS & HW & $\mathrm{CW}$ & ChW \\
\hline 1 & 409.4 & 14.33 & 342.64 & 235.25 & 42.88 & 0.45 \\
\hline 24 & 409.4 & 14.33 & 342.64 & 235.25 & 42.88 & 0.45 \\
\hline & & & & & & \\
\hline
\end{tabular}

Table 5b. The simplified final iteration of cascade analysis

\begin{tabular}{|c|c|c|c|c|c|c|}
\hline \multirow{2}{*}{ Time } & \multicolumn{6}{|c|}{ Available energy (MW) } \\
\cline { 2 - 7 } & \multirow{2}{*}{ Power } & \multicolumn{3}{|c|}{ Heat } & \multicolumn{2}{c|}{ Cool } \\
\cline { 3 - 7 } & & HPS & LPS & HW & CW & ChW \\
\hline & & & & & & \\
\hline 1 & 408.7 & 13.98 & 342.29 & 234.9 & 42.46 & 0.03 \\
\hline &. &. &. &. &. &. \\
\hline 24 & 408.7 & 13.98 & 342.29 & 234.9 & 42.46 & 0.03 \\
\hline & & & & & & \\
\hline
\end{tabular}

Table 5c. The simplified final iteration of cascade analysis

\begin{tabular}{|c|c|c|c|c|c|c|}
\hline \multirow{2}{*}{ Time } & \multicolumn{6}{|c|}{ Demand (MW) } \\
\cline { 3 - 7 } & \multirow{2}{*}{ Power } & \multicolumn{3}{|c|}{ Heat } & \multicolumn{2}{c|}{ Cool } \\
\cline { 3 - 7 } & & HPS & LPS & HW & CW & ChW \\
\hline & & & & & & \\
\hline 1 & 275 & 3 & 190.5 & 151.2 & 105.3 & 0 \\
\hline &. &. &. &. &. &. \\
\hline 24 & 0.03 & 275 & 3 & 190.5 & 151.2 & 105.3 \\
\hline & & & & & & \\
\hline
\end{tabular}

Table 5d. The simplified final iteration of cascade analysis

\begin{tabular}{|c|c|c|c|c|c|c|}
\hline \multirow{2}{*}{ Time } & \multicolumn{6}{|c|}{ Net heat requirement (MWh) } \\
\cline { 2 - 7 } & \multirow{2}{*}{ Power } & \multicolumn{3}{|c|}{ Heat } & \multicolumn{2}{c|}{ Cool } \\
\cline { 3 - 7 } & & HPS & LPS & HW & CW & ChW \\
\hline & & & & & & \\
\hline 1 & 133.7 & 10.98 & 151.79 & 83.7 & -62.84 & 0.03 \\
\hline &. &. &. &. &. &. \\
\hline 24 & 133.7 & 10.98 & 151.79 & 83.7 & -62.84 & 0.03 \\
\hline & & & & & & \\
\hline
\end{tabular}

Table 5e. The simplified final iteration of cascade analysis

\begin{tabular}{|c|c|c|c|c|c|c|}
\hline \multirow{2}{*}{ Time } & \multicolumn{5}{|c|}{ New net heat requirement (MWh) } \\
\cline { 3 - 7 } & \multirow{2}{*}{ Power } & \multicolumn{3}{|c|}{ Heat } & \multicolumn{2}{c|}{ Cool } \\
\cline { 3 - 7 } & & HPS & LPS & HW & CW & ChW \\
\hline & & & & & & \\
\hline 1 & 133.7 & 10.98 & 151.79 & 0 & -4.25 & 0.03 \\
\hline &. &. &. &. &. &. \\
\hline 24 & 133.7 & 10.98 & 151.79 & 0 & -4.25 & 0.03 \\
\hline & & & & & & \\
\hline
\end{tabular}

Table 5f. The simplified final iteration of cascade analysis

\begin{tabular}{|c|c|c|c|c|c|c|}
\hline \multirow{2}{*}{ Time } & \multicolumn{5}{|c|}{ Charging and discharging energy (MWh) } \\
\cline { 3 - 7 } & \multirow{2}{*}{ Power } & \multicolumn{3}{|c|}{ Heat } & \multicolumn{2}{c|}{ Cool } \\
\cline { 3 - 7 } & & HPS & LPS & HW & CW & ChW \\
\hline & & & & & & \\
\hline 1 & 108.3 & 6.37 & 88.04 & 0 & -7.33 & 0.02 \\
\hline &. &. &. &. &. &. \\
\hline 24 & 108.3 & 6.37 & 88.04 & 0 & -7.33 & 0.02 \\
\hline & & & & & & \\
\hline
\end{tabular}

Table 5g. The simplified final iteration of cascade analysis

\begin{tabular}{|c|c|c|c|c|c|c|}
\hline \multirow{2}{*}{ Time } & \multicolumn{6}{|c|}{ Cumulative energy (MWh) } \\
\cline { 2 - 7 } & \multirow{2}{*}{ Power } & \multicolumn{3}{|c|}{ Heat } & \multicolumn{2}{|c|}{ Cool } \\
\cline { 3 - 7 } & & HPS & LPS & HW & CW & ChW \\
\hline & 0 & 0 & 0 & 0 & 0 & 0 \\
\hline 1 & & & & & & \\
\hline & 108.3 & 6.37 & 88.04 & 0 & -7.33 & 0.02 \\
\hline 24 &. &. &. &. &. &. \\
\hline & 0.16 & 0.04 & 0.21 & -0.61 & 0.61 & 0.23 \\
\hline
\end{tabular}

Table 5h. The simplified final iteration of cascade analysis

\begin{tabular}{|c|c|c|c|c|c|c|}
\hline \multirow{2}{*}{ Time } & \multicolumn{6}{|c|}{ New cumulative energy (MWh) } \\
\cline { 2 - 7 } & Power & \multicolumn{3}{|c|}{ Heat } & \multicolumn{2}{|c|}{ Cool } \\
\cline { 3 - 7 } & & HPS & LPS & HW & CW & ChW \\
\hline & 183 & 19.07 & 308.32 & 0.61 & 43.97 & 0 \\
\hline 1 & & & & & & \\
\hline & 291.3 & 25.43 & 396.36 & 0.61 & 36.64 & 0.02 \\
\hline 24 &. &. &. &. &. &. \\
\hline & 183.2 & 19.11 & 308.54 & 0 & 44.57 & 0.23 \\
\hline
\end{tabular}

\subsubsection{Calculation of New Size of Utility in the Trigeneration System}

The new size of the utility in the trigeneration system needs to be measured in such a way that the energy difference between the initial energy and the final energy can be reduced. Minimising energy differences between initial energy and final energy will reduce costs as well as environmental energy dissipation. The new size of the utility in the trigeneration method is determined using Equation (4). Two conclusions can be drawn from the results of the study. First, the energy capacity needs to be increased if the final energy is less than the initial energy. Second, the utility capacity becomes overloaded if the final energy becomes greater than the initial energy. By using Equation (4), power, HPS, HW, CW and ChW are reduced from $600 \mathrm{MW}$ to $435.02 \mathrm{MW}$, from $50 \mathrm{MW}$ to 48.6 MW, from $250 \mathrm{MW}$ to $143.59 \mathrm{MW}$, from $200 \mathrm{MW}$ to $143.59 \mathrm{MW}$ and from $50 \mathrm{MW}$ to $25.24 \mathrm{MW}$. The sizing utility of LPS, on the other hand, need to be increased from 150 MW to $345.12 \mathrm{MW}$.

$$
S_{\text {eq(new) }}=S_{\text {eq }}-\left(E_{\text {final }}-E_{\text {initial }}\right) / T
$$


Where $\mathrm{S}_{\text {eq(new) }}=$ New sizing utility in trigeneration system in $\mathrm{MW} ; \mathrm{S}_{\mathrm{eq}}=$ Previous sizing utility in trigeneration system in $\mathrm{MW}$; $\mathrm{E}_{\text {final }}=$ Available energy for the next day in $\mathrm{MWh} ; \mathrm{E}_{\text {initial }}=$ Minimum outsourced energy supply in $\mathrm{MWh}$; $\mathrm{T}=$ Time in $\mathrm{h}$.

\subsubsection{Percentage change between new and previous sizes of utilities in the trigeneration system}

The percentage change shown in Equation (5) is used to reduce the energy gaps between the minimum outsourced energy supply to start up the system and available energy for the next day. Reducing energy gaps will give the trigeneration system an optimal size of utilities. Ho et al. [23] set a value of $0.05 \%$ as a threshold for the precision of the results. An iteration process is used in this step and will stop if the percentage change values for power, heating and cooling are below or at $0.05 \%$.

Based on the first iteration, percentage changes for power is $27.5 \%$, HPS is $2.8 \%$, LPS is $130.08 \%$, HW is $26.17 \%$, $\mathrm{CW}$ is $28.21 \%$ and $\mathrm{ChW}$ is $49.52 \%$. The calculation stops at 36 th iterations since all percentage changes of utilities are less than $0.05 \%$. Based on the final iteration, the new power, HPS, LPS, HW, CW and $\mathrm{ChW}$ in the trigeneration system are 409.4 MW, 14.33 MW, 342.64 MW, 235.28 MW, 42.86 MW and 0.45 MW.

$$
P=\left(S_{\text {eq(new })}-S_{\text {eq }}\right) / S_{\text {eq }} \times 100 \%
$$

Where $\mathrm{P}=$ Percentage change between new and previous sizing of utilities in the trigeneration system; $\mathrm{S}_{\mathrm{eq}(\text { new })}=$ New sizing utilities in trigeneration system in $\mathrm{MW} ; \mathrm{S}_{\mathrm{eq}}=$ Previous sizing utilities in trigeneration system in MW.

\section{Conclusions}

A modified numerical method based on Pinch Analysis called TriGenSCA by considering transmission and storage energy losses have been developed to determine the exact value of required energy by the centralised trigeneration system to supply to the demands. Energy losses due to frictional in the transmission lines as well as charging and discharging of energy into and out of storage systems are considered. A comparison has been made with the same case study of the trigeneration system without considering transmission energy losses. An additional $3 \mathrm{MW}$ or $0.1 \%$ of energy is required by the trigeneration system to supply sufficient energy to meet the demand needs. The TriGenSCA will give an optimum utility size in the trigeneration system by reducing the energy differences between the final and the initial energy value of the trigeneration system.

\section{Acknowledgements}

The authors would like to thank Universiti Teknologi Malaysia and the Ministry of Higher Education of Malaysia for the financial support provided under Skim Latihan Akademik Bumiputera (SLAB) and the Research University Fund under Vote Numbers
Q.J130000.2546.18H90， Q.J13000.2509. 19H34, Q.J130000.21A2.04E44 and Q.J13000.3509.05G96.

The authors also gratefully acknowledge the EC project fund No. CZ.02.1.01/0.0/0.0/15 003/0000456, provided to the Sustainable Process Integration Laboratory-SPIL, which is funded as the Operational Programme Research, Development and Education of the Czech Ministry of Education, Youth and Sports by EU European Structural and Investment Funds, Operational Programme Research, Development and Education under a collaboration agreement with Universiti Teknologi Malaysia.

\section{References}

1. World Energy Council. World Energy Scenarios 2019. Available from: https://www.worldenergy. org/assets/downloads/Scenarios_Report_FINAL_for _website.pdf (2019)

2. D.W. Wu, R.Z. Wang, Combined Cooling, Heating and Power: A Review. Progress Energy Combustion. 32, 459 - 495 (2006)

3. E. Cardona, A.A. Piacentino, methodology for sizing a trigeneration plant in Mediterranean areas. Applied Thermal Engineering. 23 (13), 1665 - 1680 (2003)

4. S. Plura, C. Kren, C. Schweigler, Efficient and flexible tri-generation with two-stage absorption chiller. American Society of Mechanical Engineers, IMECE, ASME, IMECE-15900, Chicago, IL, USA, 189-197 (2006)

5. A. Rong, R. Lahdelma, P.B. Luh, Lagrangian relaxation based algorithm for trigeneration planning with storages. European Journal of Operational Research 188(1):240-257 (2008)

6. F.A. Al-Sulaiman, F. Hamdullahpur, I. Dincer, Efficiency and environmental impact assessments of a trigeneration plant using sofc and orc. Proceedings of the Global Conference on Global Warming, Istanbul, Turkey, 11 (2009)

7. S. Bracco, G. Dentici, S. Siri, DESOD: a mathematical programming tool to optimally design a distributed energy system. Energy, 100, 298-309 (2016)

8. I.H.V. Gue, A.T. Ubando, K.B. Aviso, R.R. Tan, Optimal design of a trigeneration plant using fuzzy linear programming with global sensitivity analysis on product price uncertainty. Energy Proc. 158, 2176-2181 (2019)

9. K. Jamaluddin, K.; S.R. Wan Alwi, Z. Abdul Manan, K. Hamzah, J.J. Klemeš, A Process Integration Method for Total Site Cooling, Heating and Power Optimisation with Trigeneration Systems. Energies, 12(6), 1030 (2019)

10. K. Jamaluddin, S.R. Wan Alwi, K. Hamzah, J.J. Klemeš, A Numerical Pinch Analysis Methodology for Optimal Sizing of a Centralised Trigeneration System with Variable Energy Demands. Energies, 13(8), 2038 (2020) 
11. I. Khamis, T. Koshy, K.C. Kavvadias, Opportunity for cogeneration in Nuclear Power Plants. The 2013 World Congress on Advances in Nano, Biomechanics, Robotics, and Energy Research (ANBRE13). Seoul, Korea. August 25 - 28 (2013)

12. X. Luo, J. Wang, M. Donner, J. Clarke, Overview of current development in electrical energy storage technologies and the application potential in power system operation. Applied Energy. 137, 511 - 536 (2015)

13. M. Bragard, N. Soltau, S. Thomas, R.W. de Doncker, The Balance of Renewable Sources and User Demands in Grids: Power Electronics for Modular Battery Energy Storage Systems. IEEE Trans. Power Electron. 25, 3049-3056 (2010)

14. Types of Steam Turbine. Available online: https://www.sciencedirect.com/topics/engineering/ty pes-ofsteam-turbine (accessed on 1 January 2020).

15. K. Zhu, X. Chen, B. Dai, Y. Wang, X. Li, L. Li, Experimental study on the thermal performance improvement of a new designed condenser with liquid separator. Energy Procedia, 104, 269-274 (2016)

16. R. Best, W. Rivera, A review of thermal cooling systems. Applied Thermal Engineering, 75, 11621175 (2015)
17. J.D. Hobby, G.H. Tucci, Analysis of the residential, commercial and industrial electricity consumption. 2011 IEEE PES Innovative Smart Grid Technologies. Pp. 1 - 7 (2011)

18. Spirax Sarco. Pipes and pipe sizing. Available from: https://beta.spiraxsarco.com/learn-aboutsteam/steam-distribution/pipes-and-pipe-sizing. (accessed on 23.4.2019)

19. B-C. Han, W-L. Cheng, Y-Y Li, Y-L Nian, Thermodynamic analysis of heat driven combined cooling heating and power system (CCHP) with energy storage for long distance transmission. Energy Conversion and Management. 154, 102 - 117 (2017)

20. M. Reta-Hernandez, Transmission Line Parameters. Universidad Autónoma de Zacatecas: Taylor \& Francis Group, LLC (2006)

21. B. Linnhoff, J.R. Flower, Synthesis of heat exchanger networks: I. Systematic generation of energy optimal networks. AIChE Journal. 24, 633 - 642 (1978)

22. P.Y. Liew, S.R. Wan Alwi, P.S. Varbanov, Z.A. Manan, J.J. Klemeš, A numerical technique for Total Site sensitivity analysis. Applied Thermal Engineering. 40, 397 - 408 (2012)

23. W.S. Ho, H. Hashim, M.H. Hassim, Z.A. Muis, N.L.M. Shamsuddin, Design of distributed energy system through Electric System Cascade Analysis (ESCA). Applied Energy. 99, 309 - 315 (2012) 